\title{
A IMPLEMENTAÇÃO DE POLÍTICAS DO BANCO MUNDIAL PARA A FORMAÇÃO DOCENTE
}

\author{
LUCÍOLA LICINIO DE C. P. SANTOS
}

Faculdade de Educação da Universidade Federal de Minas Gerais - UFMG

\section{RESUMO}

Este trabalho tem como objetivo identificar as convergências e divergências no desenvolvimento das propostas de educação continuada, financiadas pelo Banco Mundial - BM -, tomando como referencial as experiências de Minas Gerais e de São Paulo. Por um lado, existem evidências de que esses estados elaboraram suas propostas de formação continuada financiadas pelo Banco Mundial, incorporando em grau diferenciado as orientaçóes deste órgão, pois não foi concedido o mesmo grau de autonomia às universidades e aos estabelecimentos de ensino que deles participaram. Por outro lado, pesquisas realizadas no campo da formação continuada têm apontado para questôes que não foram consideradas nesses projetos e em sua implementação. Para discutir tais questões, o trabalho analisa, de início, as concepções de formação docente presentes nos documentos do BM. A seguir são discutidas as experiências de Minas Gerais e de São Paulo, procurando identificar permanências e rupturas com as propostas do banco. Finalmente, com base na literatura sobre formação continuada são analisados alguns dos resultados e conseqüências da implementação dos projetos nos dois estados mencionados.

EDUCAÇÃO CONTINUADA - FORMAÇÃO DE PROFESSORES - BANCOMUNDIAL

\section{ABSTRACT}

THE IMPLEMENTATION OF WORLD BANK POLICIES FOR TEACHING REFORM. This article aims to identify the concurrences and divergences in the development of proposals for continuing education, financed by the World Bank - IBRD -, taking the experiences of Minas Gerais and São Paulo as a reference. On the one hand, there exists evidence that these states are elaborating their proposals for continuing education financed by the World Bank, incorporating the orientations of the institution to differing degrees, since the same degree of autonomy of the universities and to the teaching establishments in which they participate. On the other hand, research in the field of continuous education have pointed to issues that were not taken into consideration in these projects and their implementation. To discuss such issues, the article, from the outset, analyzes concepts of teacher training in World Bank documents. Following that, the experiences of Minas Gerais and São Paulo are discussed, seeking to identify continuities and ruptures with the Bank's proposals. Finally, based in the literature on continuing education, some of the results and consequences of implementing projects in the two states mentioned are discussed.

A idéia central e condutora deste trabalho é que, apesar de os empréstimos do 
BM serem concedidos em razão da adesão a suas políticas e da aceitação de suas orientações na elaboração e execução de projetos, esse processo desenvolve-se de maneira mais complexa e não de forma linear e vertical, como parece à primeira vista. Entende-se que as secretarias de estado da educação, assim como os demais envolvidos no processo, possuem culturas, práticas e concepções, no campo educacional, que podem apresentar diferenças em relação às propostas do BM, interferindo na forma como os projetos são pensados e implementados. Considerando o papel ativo dos atores sociais participantes, pode-se dizer que em cada instância de realização dos programas, as propostas de trabalho são recontextualizadas, de acordo com as tradições e a cultura local. Dessa forma, resultados imprevistos podem ocorrer, bem como muitos dos objetivos propostos no início do trabalho podem não ser alcançados. Seguindo esse raciocínio, haveria espaços a serem considerados no desenvolvimento dos programas que, se devidamente ocupados, poderiam favorecer a emergência de concepções e práticas mais coerentes com os interesses reais da escola pública. No entanto, algumas questões levantadas pela literatura sobre formação docente levam ao questionamento da possibilidade de tais programas proporcionarem a concretização de concepções e práticas desejadas por aqueles que partilham de ideais mais enraizados em uma tradição progressista e crítica no campo educacional, devido às limitações decorrentes dos próprios critérios definidos pelas propostas.

\section{POLÍTICA DO BANCO MUNDIAL SOBRE FORMAÇÃO DOCENTE}

Partindo das necessidades econômicas, geradas no setor produtivo e nas formas como ele se estrutura e se organiza, o BM destaca o papel da educação para o desenvolvimento das sociedades contemporâneas. Depois de mostrar as altas taxas de retorno trazidas por investimentos no campo educacional, o BM define políticas, nesse campo, para os países do terceiro mundo com o objetivo de melhorar a sua competitividade no mercado internacional. Identificando a distribuição desigual e a baixa qualidade da educação oferecida à maioria da população dos países em desenvolvimento, o BM, segundo Coraggio (1996), defende a idéia da eqüidade em educação, como condição para eficiência econômica global. É importante ressaltar, no entanto, que o conceito de eqüidade adotado pelo BM tem sido objeto de análise crítica, no Brasil, por alguns estudos no campo das políticas públicas (Oliveira, 1999; Paiva, Warde, 1994; Fonseca, 1996). Essa eqüidade, para o BM, seria dada pela universalização do ensino fundamental, o que em termos econômicos acarretaria uma demanda além daquela prevista para o trabalho, produzindo uma força de trabalho mais qualificada e que pode ser mantida com salários mais baixos. Além da prioridade do ensino básico para o desenvolvimento econômico, o 
BM também discute a necessidade de melhorar a qualidade da educação para esse nível. De acordo com Torres ( 1996), a qualidade do ensino para o BM depende da presença de alguns fatores determinantes de um processo mais efetivo de aprendizagem. Dentre esses fatores, o BM prioriza três: o aumento do tempo de instrução, a melhoria do livro didático e a capacitação em serviço dos docentes.

Serão agora discutidos os principais aspectos das propostas do BM para a formação docente, com base nos trabalhos de Torres (1996) e de Lauglo (1997). Em primeiro lugar, o BM prioriza a educação continuada sobre a educação inicial. Como já foi ressaltado por Santos ( 1998), a ênfase dada pelo banco à formação continuada é decorrente de uma análise que privilegia aspectos econômicos, baseada em estudos de custobenefício, em que a formação docente é pensada em termos da melhor forma de se produzir um profissional competente tecnicamente. Nesse sentido, a educação em serviço apresenta-se como forma mais barata e mais eficiente de formar profissionais para a educação. A redução da educação inicial e o investimento na educação continuada são, pois, compatíveis com um projeto educacional de viés econômico, fundamentado em uma visão técnica e instrumental da educação. Para os que defendem melhorias no campo educacional, relacionando-as com o desenvolvimento de um projeto social, ligado a ideais democráticos, a formação inicial é valorizada na medida em pode dotar os docentes de capacidade crítica e criadora, pelo estudo, pela discussão e pela análise do processo de ensino-aprendizagem e de todos os seus condicionantes políticos, econômicos, sociais e culturais. O investimento na educação continuada é proposto pelo banco, na perspectiva de melhorar o desempenho docente mediante maior domínio que o professor/a venha a ter dos conteúdos das disciplinas e de estratégias pedagógicas para ministrá-las, instrumentalizando o docente para seguir diretrizes e normas curriculares. A competência pensada em termos de autonomia, que exige formação técnica e política, faz parte da agenda daqueles comprometidos com uma educação fundada na idéia de emancipação.

Em segundo lugar, o BM privilegia na educação continuada o conhecimento do conteúdo das matérias, alegando que ele tem mais influência no rendimento dos alunos do que o conhecimento pedagógico que os professores venham a ter. Além disso, o banco preconiza o uso da educação a distância, tendo em vista ser o seu custo menor, se comparado com modalidades presenciais. Contudo, a pesquisa em educação tem mostrado que não é possível, no campo do ensino, dissociar o conteúdo das formas como este é abordado, sendo de fundamental importância nesse processo considerar-se a influência de valores e compromissos éticos dos docentes e da cultura organizacional da escola. Em relação à educação a distância, pode-se argumentar que não existem, ainda, evidências baseadas em pesquisas que possibilitem afirmações confiáveis sobre os resultados do uso dessa modalidade de ensino no processo de formação continuada de 
docentes.

\section{PROPOSTA DE EDUCAÇÃO CONTINUADANO ESTADO DE SÃO PAULO}

No Estado de São Paulo, o Programa de Educação Continuada - PEC - foi desenvolvido no ano de 1998, voltando-se, primordialmente, para os professores do ensino fundamental. Inicialmente, a Secretaria de Educação lançou um documento contendo as diretrizes gerais do PEC e abriu concorrência pública dirigida às instituições voltadas para o campo da formação de professores, como universidades e instituições congêneres, para que pudessem inscrever suas propostas, de acordo com os objetivos traçados por aquele órgão. Diferentes instituições públicas e privadas se inscreveram como agências capacitadoras e várias tiveram suas propostas aceitas. As propostas apresentadas foram bem diversificadas, voltandose tanto para o ensino de diferentes disciplinas ou de áreas de estudo, como para questões pedagógicas e administrativas das escolas, envolvendo, em alguns casos, todo o corpo docente e administrativo dos estabelecimentos escolares e, em outros, parte desses. Para isso, foram previstas atividades denominadas "centralizadas" e dirigidas às lideranças educacionais, incluindo desde delegados e técnicos das delegacias de ensino até a direção e a coordenação pedagógica das escolas. As atividades do chamado nível "descentralizado" estavam voltadas para ações destinadas ao conjunto dos professores das escolas.

Diante da oferta de cursos, as delegacias de ensino, a partir de consulta feita às escolas, selecionaram aqueles oferecidos por instituições localizadas próximas aos municípios pertencentes às diferentes delegacias. A carga horária de trabalho com os professores foi definida como sendo de 96 horas, distribuídas em quatro módulos de 24 horas, a serem oferecidos para turmas de 35 professores. Alguns cursos não tiveram continuidade porque, ao final de cada módulo, os cursos passaram por um processo de avaliação que determinava, ou não, o seu prosseguimento.

A primeira observação a ser feita é que a Secretaria de Educação determinou que o PEC deveria ser planejado e implementado a partir de um modelo circular de educação continuada, baseado no esquema ação-reflexão-ação, possibilitando, dessa forma, uma estreita vinculação com os problemas vividos pelos docentes em seu cotidiano de trabalho. Além disso, a proposta de educação continuada faria parte de um programa mais amplo que incluiria desde a democratização da gestão escolar até a melhoria das instalações e do equipamento escolar.

O segundo ponto a ser levantado é que algumas agências capacitadoras ofereceram cursos destinados ao conjunto dos professores e das lideranças esco- 
lares, entendendo que os processos de mudança tornam-se mais viáveis quando dirigidos a toda comunidade escolar. No entanto, como já foi dito, a maior oferta foi de cursos sobre determinados conteúdos curriculares, sobre metodologias de ensino ou sobre questões vinculadas à disciplina e outros problemas presentes nas escolas.

Por último, é importante registrar que, apesar de os professores capacitadores só receberem pagamento pelas atividades desenvolvidas nos módulos, alguns deles visitaram as escolas, com o objetivo de oferecer maior suporte ao trabalho dos docentes, e estabelecer melhor dinâmica de trabalho, a partir do conhecimento das situações vivenciadas pelos docentes nas escolas.

\section{PROPOSTA DE EDUCAÇÃO CONTINUADA DESENVOLVIDA EM MINAS GERAIS}

No Estado de Minas Gerais foi desenvolvido por meio da Secretaria de Educação um projeto de educação continuada denominado Programa de Capacitação de Professores - Procap -, voltado para as escolas da redes estadual e municipais do ensino fundamental. Segundo o Guia de Estudo Geral, o Procap seria efetivado por uma ação conjunta, do poder público estadual e municipal, por meio das secretarias de educação e das instituições de ensino superior. $\bigcirc$ programa foi organizado em duas fases. Na primeira, já realizada, no ano de 1998, foram oferecidos cursos abordando os conteúdos básicos de Português, Matemática e Reflexões sobre a Prática Pedagógica.

Segundo representante de uma superintendência educacional, citada em trabalho de pesquisa sobre educação continuada, realizado por Pena (1999), o objetivo do Procap é capacitar o docente para as novas propostas pedagógicas que incluem o trabalho com ciclos, a interdisciplinaridade e novas formas de avaliação.

Depois de preparar o material videográfico e as diretrizes gerais de trabaIho, a Secretaria de Educação abriu concorrência pública para escolher a instituição especializada que coordenaria o programa no estado. A instituição preparou o material escrito e a partir daí, mais uma vez, por meio de concorrência pública, com base em projeto de trabalho, foram escolhidas as instituições "pólos" que coordenaram o processo em diferentes regiões abrangendo os municípios das superintendências educacionais mais próximas a elas. A instituição especializada treinou os professores monitores ligados às diferentes instituições de ensino superior (instituições "pólos") e essas, por sua vez, treinaram os "facilitadores" que eram professores das escolas que coordenavam o trabalho no interior dos esta- 
belecimentos de ensino.

A capacitação dos docentes nas escolas deveria abranger uma carga horária de 180 horas, distribuída em 19 semanas, com atividades presenciais e não presenciais. Os encontros nas escolas teriam a duração de duas horas e meia e deveriam ocorrer fora do horário de trabalho. Para a sua realização foram programadas atividades, abrangendo apresentações de vídeos, acompanhadas de debates, e também a preparação de planos de trabalho, voltados para a prática docente e para a realização de discussões sobre planos executados. Além disso, previramse duas horas e meia de atividades não presenciais, em que os professores deveriam realizar estudos que incluíam leituras, elaboração de resumos, esquemas, utilizando o material fornecido pelo programa.

A participação no programa atingiu um maior número de professores da rede estadual, uma vez que eles receberiam do estado uma pequena ajuda de custo para despesas com locomoção. Como poucas prefeituras conseguiram oferecer a ajuda, houve menor adesão dos professores da rede municipal ao programa.

Em algumas universidades os professores monitores realizaram atividades que não estavam previstas no Procap, como oficinas de trabalho, visando complementar o programa. Também, os monitores das universidades, no contato com as escolas, para acompanhamento do trabalho, algumas vezes, eram solicitados a dar explicações sobre os conteúdos trabalhados nos cursos.

\section{CONCLUSÃO}

Em primeiro lugar, é importante deixar registrado que algumas instituições não quiseram participar desses programas de formação continuada por serem financiados pelo Banco Mundial e, mesmo no interior de algumas daquelas que participaram do programa, grupos de professores ou docentes isolados se recusaram a fazê-lo pela mesma razão. Isso não quer dizer que as instituições e os professores que aderiram às propostas estejam alinhados com a política do banco. Como foi visto, sobretudo no Estado de São Paulo, as instituições capacitadoras tiveram autonomia para realizar suas propostas, e uma boa parcela delas estava enraizada nos princípios e nas experiências dos grupos de docentes que nelas atuaram, sintonizando-se com uma tradição pedagógica mais crítica e afastandose, dessa forma, das diretrizes traçadas pelo BM.

Como foi anunciado no início deste trabalho, no processo de negociação dos programas financiados pelo BM, há possibilidade de que a tradição e a cultura dos órgãos envolvidos venham a ter uma certa influência nos programas, levando 
a modificações e transformações dos princípios e diretrizes traçados pelo BM. Desta forma, pode-se dizer que a condução do projeto de educação continuada desenvolvido em São Paulo concedeu um grau maior de autonomia às agências capacitadoras. A própria Secretaria de Educação estabeleceu diretrizes mais vinculadas à tradição do Estado nesse campo do que em Minas Gerais, onde, como foi visto, o programa de educação continuada assentou-se sobre os pilares básicos erigidos pelo BM, ou seja, conhecimento dos conteúdos das matérias pelos professores atendidos e uso de metodologias de trabalho que envolvam a educação a distância. Além disso, em Minas Gerais, as decisões sobre o processo de trabalho foram tomadas de forma bastante centralizada, deixando pequena margem de autonomia para as agências executoras do projeto.

De qualquer forma, com maior intensidade em São Paulo do que em Minas, pode-se dizer que houve um processo de recontextualização das diretrizes do BM que levou a resultados diferentes daqueles previstos pelos documentos do banco. Acrescente-se a isso que no próprio processo de recepção dos cursos, os professores em treinamento não apenas incorporaram os conhecimentos e habilidades previstos de forma diferenciada e estreitamente relacionada com suas experiências prévias, mas também utilizaram o próprio espaço dos cursos para atividades não previstas, como a troca de experiências, a crítica coletiva, muitas vezes paralela e não perceptível para monitores e professores, sobre a validade ou não daquilo que estava sendo apresentado (Pena, 1999).

Sobre a eficiência dos cursos, que buscaram modificações da prática docente, é importante tecer algumas considerações. A literatura sobre formação em serviço tem enfatizado a necessidade de se trabalhar com o conjunto dos professores das escolas, com vistas a uma modificação coletiva das práticas nelas instaladas, uma vez que o trabalho, envolvendo apenas parte do corpo docente, pode ser dificultado, tanto pela não-modificação da dinâmica de trabalho na instituição, como pela ação de docentes não-sensibilizados para mudanças. Tem sido também apontado pela literatura que os processos de formação continuada centrados nos problemas cotidianos dos docentes, em que a teoria é utilizada como instrumento para a sua compreensão, são mais efetivos dos que os chamados de formação do tipo escolar, que exploram mais aspectos teóricos, pouco sintonizados com a realidade cotidiana das escolas. Nesse sentido, os programas de formação devem se constituir em processos realmente contínuos, e não em atividades pontuais desenvolvidas esporadicamente.

Nos programas de educação continuada de Minas Gerais e São Paulo, apesar de, em alguns casos, envolverem todos os professores de uma escola, esta não 
foi a tônica. Em São Paulo, sobretudo, os professores apontaram a falta de espaço nas escolas para desenvolver idéias trabalhadas nos cursos como um aspecto extremamente negativo para a incorporação efetiva das propostas apresentadas, o que já identifica um grande problema para esses projetos. Além disso, as próprias universidades, pela sua tradição, têm mais facilidade de trabalhar com aspectos teóricos do que com os problemas práticos das escolas. No entanto, é importante ressaltar que os docente de muitas universidades, assim como os coordenadores dos programas dessas instituições, afirmaram que os projetos de educação continuada possibilitaram maior conhecimento dos problemas vivenciados pelas redes públicas de ensino, o que favorece a incorporação dessas experiências aos cursos de formação inicial, oferecidos pelas instituições. Esse é também um resultado inesperado, que contribui para a melhoria dos cursos iniciais de formação docente, tão duramente criticados pela sua desarticulação com a realidade escolar.

Como pode ser visto, uma tentativa de análise da eficiência desses cursos, a médio e longo prazo, é bastante complexa. Sabe-se que, a curto prazo, é mais perceptível o impacto dos cursos de formação em serviço, pois muitos docentes costumam utilizar algumas das propostas ou atividades neles apresentadas, logo após a sua freqüência. A literatura educacional, contudo, salienta que, ao longo do tempo, geralmente, os docentes tendem a abandonar mudanças efetuadas em sua rotina, se elas não estiverem relacionadas a um projeto mais amplo de modificação das práticas escolares. Esses projetos, por sua vez, desenvolvem-se com maior sucesso, se houver um investimento constante de realimentação do processo, o qual, geralmente, se caracteriza por períodos de fluxo e refluxo, que precisam ser bem compreendidos e analisados, se o objetivo é realmente a transformação do trabalho docente.

Pode-se também argumentar que mesmo uma pequena modificação da prática dos docentes pode ter um efeito em cascata, levando gradativamente a outras mudanças. No mesmo sentido, é possível também se afirmar que ainda que não se alcancem de imediato os objetivos pretendidos, os cursos de formação continuada como o Procap e o PEC criam potenciais de mudança, que poderão ser acionados em momentos posteriores, diante de novas dificuldades, ou a partir da articulação de grupos de docentes, no interior das escolas, interessados na melhoria do trabalho pedagógico. Situações como essas podem ser capitalizadas por uma liderança competente que saiba utilizar o interesse desencadeado, ou a sensibilização realizada por programas como o Procap e o PEC, para a implementação de reformas desejáveis no interior dos estabelecimentos de ensino. Nesse contexto, é importante analisar se as mudanças ocorridas significam uma real meIhoria da qualidade de ensino, proporcionando uma educação mais inclusiva, so- 
bretudo para os grandes contingentes de alunos que têm recebido uma educação bastante precária, considerando-se os objetivos da educação básica.

Entende-se que o maior otimismo ou pessimismo em relação a projetos como esses depende do quadro interpretativo daqueles que os analisam. Para alguns, tais programas interessam mais às lideranças educacionais que os implementam, tanto para efeito de propaganda política, como pelos ganhos adicionais, acadêmicos e financeiros que proporcionam àqueles que participam de seu planejamento e de sua implementação. Os motivos alegados são que medidas pontuais não resolvem os problemas das escolas, que dependem de políticas mais amplas e globais.

Um outro grupo de acadêmicos, partindo de outra linha de análise, tende a apontar nesses projetos alguns aspectos positivos e resultados inesperados, produzidos pela ação dos atores sociais neles envolvidos. Nesse sentido, torna-se difícil concluir em que medida programas como o Procap e o PEC estão realmente contribuindo para a melhoria do ensino.

Somente a médio e a longo prazo poderá ser analisado com mais rigor o real impacto dos programas no trabalho de sala de aula. Contudo, é possível afirmar-se, hoje, que com os mesmos recursos, não vinculados a projetos como os do BM, orientados por diretrizes externas, as escolas poderiam ter maior possibilidade de criar e implementar programas mais condizentes com sua realidade, expectativa e necessidade do corpo docente.

\section{REFERÊNCIAS BIBLIOGRÁFICAS}

CORAGGIO, J.L. Desenvolvimento humano e educação. São Paulo: Cortez, 1996.

FONSECA, M. O Financiamento do Banco Mundial à educação brasileira: vinte anos de cooperação internacional. In: TOMASI, L. et al. O Banco Mundial e as políticas educacionais. São Paulo: Cortez, PUC, 1996. p. 229-5I.

LAUGLO, J. Críticas às prioridades e estratégias do Banco Mundial para a educação. Cadernos de Pesquisa, n. 100, p. I1-36, mar. 1997.

OLIVEIRA, D.A. As Reformas em curso nos sistemas públicos de educação básica: empregabilidade e eqüidade social. In: OLIVEIRA, D.A., DUARTE, M.R.T. (orgs.). Politica e trabalho na escola. Belo Horizonte: Autêntica, 1999. p. 69-97.

PAIVA, V., WARDE, M.J. Novo paradigma de desenvolvimento e centralidade do ensino básico. In: PAIVA, V. (org.). Transformação produtiva e equidade: a questão do ensino básico. Campinas: Papirus, 1994. p. 9-40. 
PENA, G.A.C. A Formação continuada de professores e suas relações com a prática docente. Belo Horizonte, 1999. Dissert. (mestr.) Faculdade de Educação da UFMG.

SANTOS, L.L.C.P. Dimensões pedagógicas e políticas da formação continua. In: VEIGA, I. P. A. (org.). Caminhos da profissionalização do magistério. Campinas: Papirus, 1998, p. 123-36.

TORRES, R.M. Melhorar a qualidade da educação básica? As estratégias do Banco Mundial. In: TOMASI, L. et al. O Banco Mundiale as politicas educacionais. São Paulo: Cortez, PUC, 1996. p. 125-93. 